
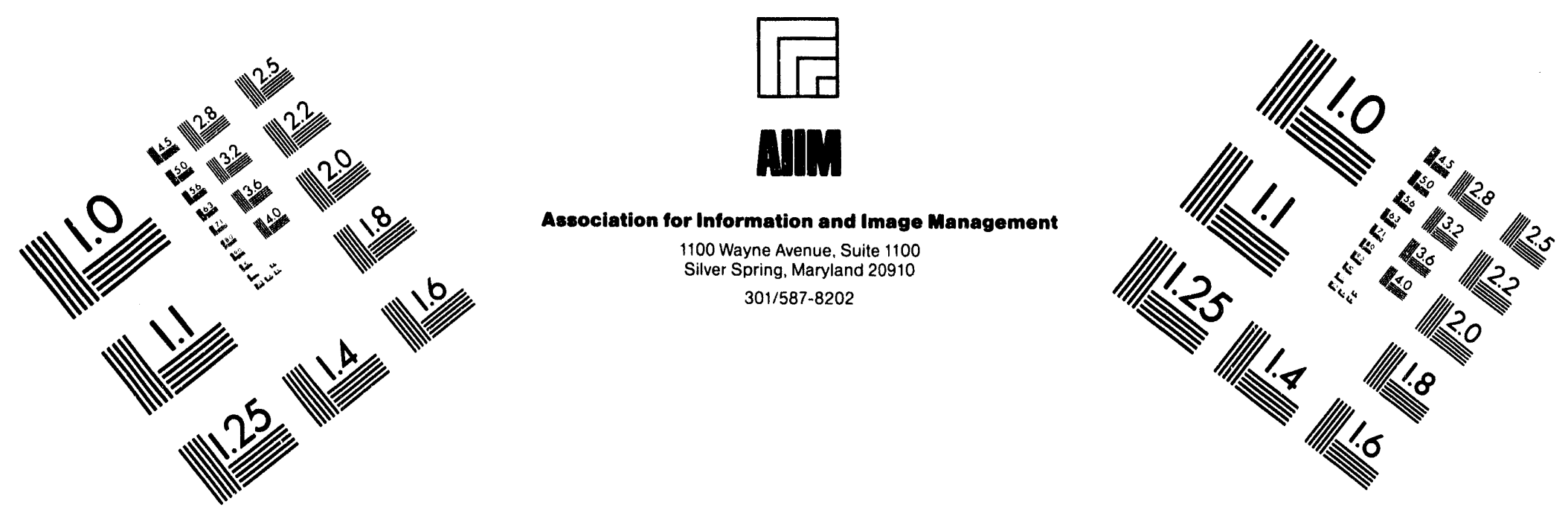

\title{
Centimeter
}

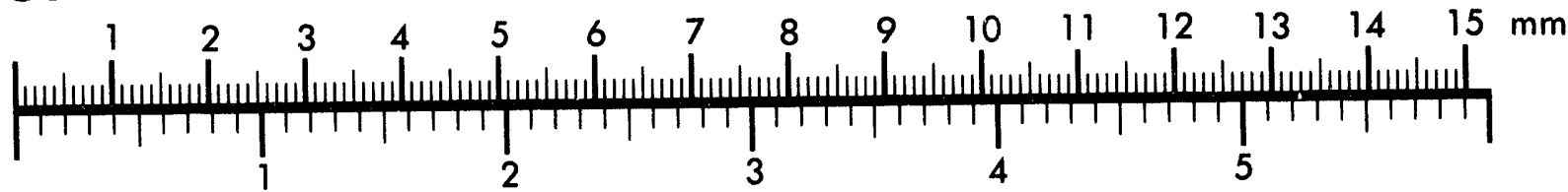
Inches
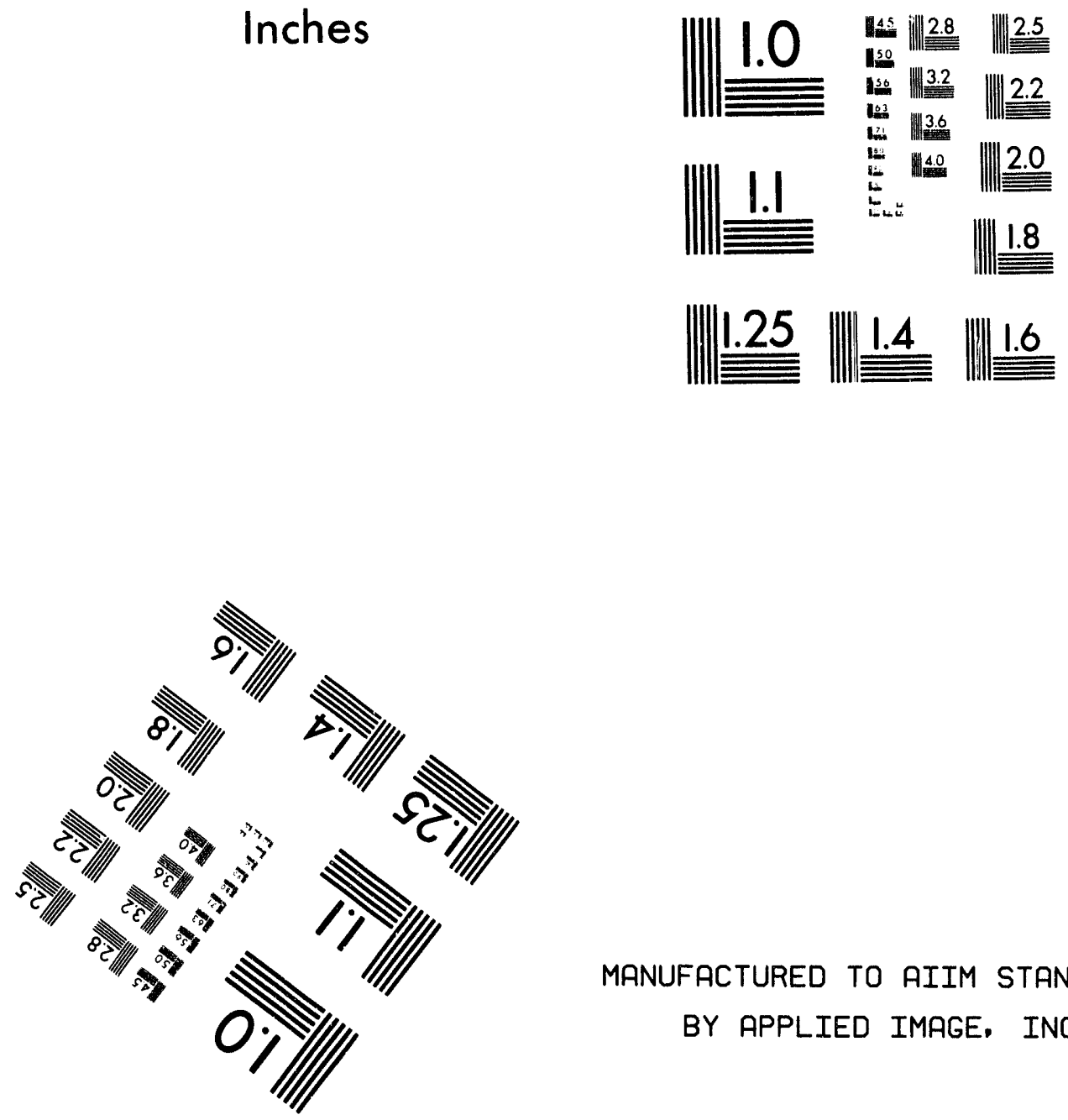

MANUFACTURED TO AIIM STANDARDS BY APPLIED IMAGE. INC.

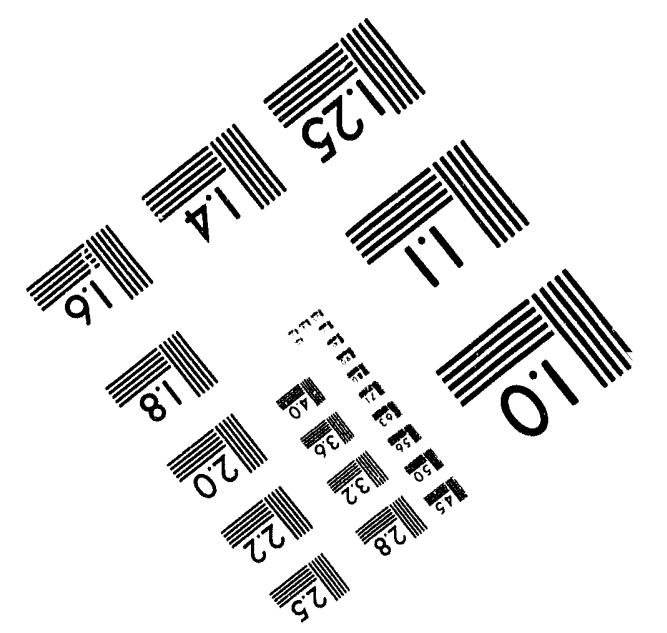



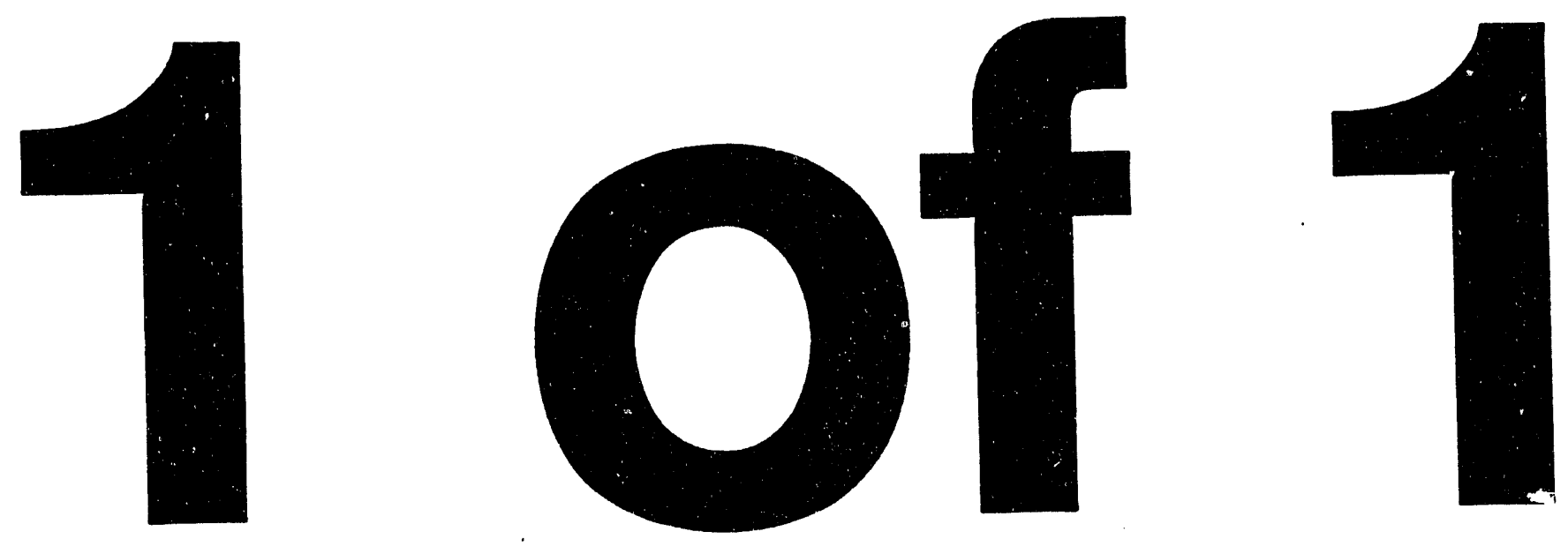
LA'ÛR-94- 2063

\author{
\begin{tabular}{l|l} 
TITLE: & USE OF MAGNESIUM FOR RECOVERING HYDROGEN \\
ISOTOPES FORM TRITIATED WATER
\end{tabular} \\ AUTHOR(S): \\ R. Scott Willms \\ ESA-3 \\ Sotoshi Konishi \\ JAERI \\ Kenji Okuno \\ JAERI
}

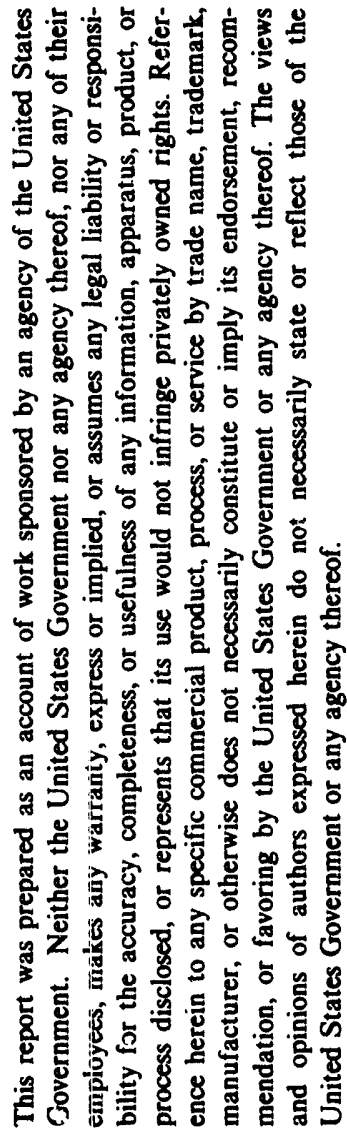

IITTED TO:

11TH TOPICAL MEETING ON THE TECHNOLOGY OF FUSION ENERGY

JUNE 19-23, 1994 - NEW ORLEANS, LOUISIANA
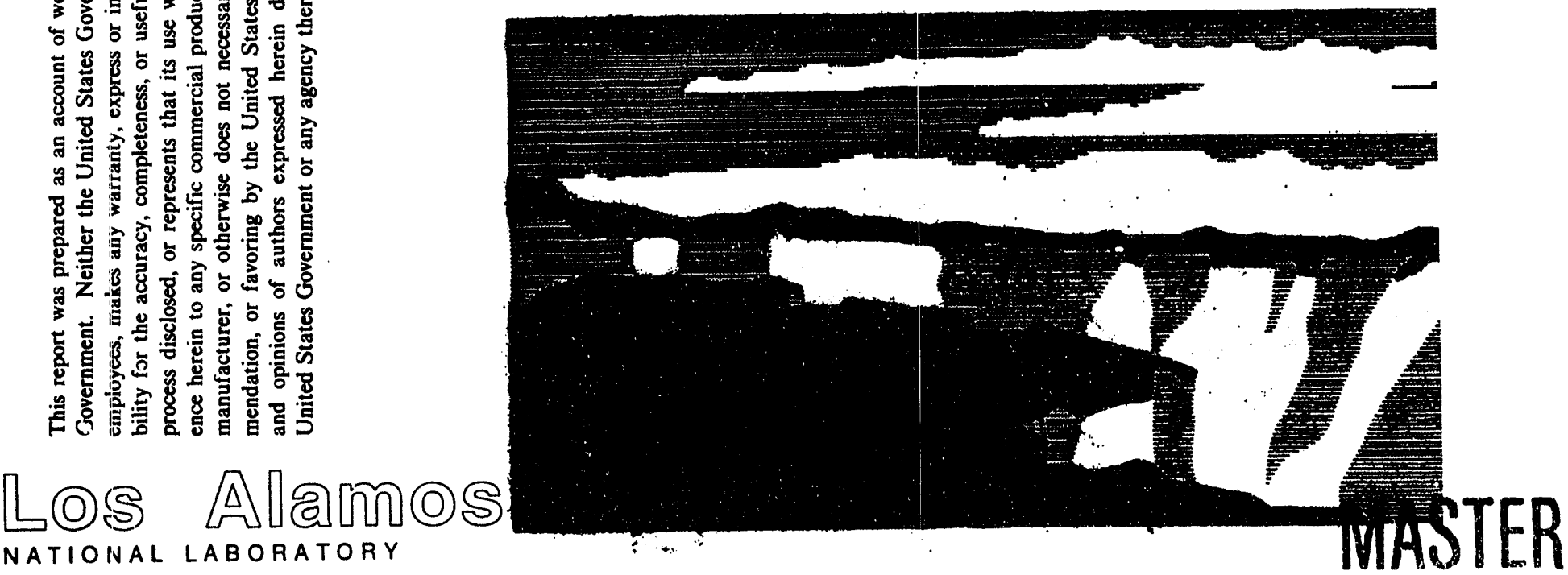

NATIONAL LABORATORY

Los Alamos National Laboratory, an affirmative action/equal opportunity employer, is operated by the University of Califomia for the U.S. Department of Energy Los Alamos National Laboricense to under contract W-7405-ENG-36. By acceptance of this article, the publisher recognizes that the Government purposes. The Los Alamos National Laboratory requests that the publisher identify this article as work performed under the auspices of the U.S. Department of Energy. 


\section{USE OF MAGNESIUM FOR RECOVERING HYDROGEN ISOTOPES FROM TRITIATED WATER}

\author{
R. Scott Willms \\ Los Alamos National Laboratory \\ P. O. Box 1663 \\ Los Alamos NM 87545 \\ 505-667-5802
}

\author{
Satoshi Konishi \\ Japan Atomic Energy Research \\ Institute \\ Tokai-mura, Naka-gun, Ibaraki- \\ ken, 319-11, Japan
}

\author{
Kenji Okuno \\ Japan Atomic Energy Research \\ Institute \\ Tokai-mura, Naka-gun, Ibaraki- \\ ken, 319-11, Japan
}

\section{ABSTRACT}

Reacting tritiated water with hot metal to recover the tritium from tritiated water has been practiced for considerable time. A metal frequently used for this purpose has been uranium. Recent work at the Tritium Systems Test Assembly at Los Alamus National Laboratory has focused on using magnesium for this purpose. This work was done as part of the Annex IV collaboration between the US Department of Energy/TSTA and the Japan Atomic Energy Research Institute/Tritium Processing Laboratory. Magnesium appears to have reactive properties that are as good as uranium and possibly better, and, of course, magnesium is easier to handle and less strictly controlled. Both bench-scale and practical-scale experiments were conducted with magnesium, including tests with tritiated water. $\mathrm{Mg}$ bed construction techniques and operating parameters were determined. Testing showed that the $\mathrm{Mg}$ packed bed was very effective for recovering hydrogen isotopes from water. However, when used for this purpose, either $\mathrm{Mg}$ or $\mathrm{U}$ is irreversibly consumed and must be disposed of as tritiated waste. It follows that this processing technique would be inappropriate for a large tritiated water processing operation. However, this technique may find utility for small-scale systems.

\section{INTRODUCTION}

The first fusion reactors are expected to be fueled with deuterium-tritium (DT). Tritium is radioactive and of high value (currently about $\$ 30,000 / \mathrm{gm}$ ). Thus, if a significant portion of the tritium is oxidized to water, a processing step is required to recover this tritium. Tritium may be oxidized due to contact with oxygen in the fusion reactor. Further, tritium may be oxidized intentionally since it is relatively easy to oxidize tritium in various forms (e.g. elemental hydrogen isotopes, hydrocarbons, ammonia) to water. Then, water can be separated from the remaining gases (e.g. carbon oxides, nitrogen, helium, argon, etc.) so only one component, water, needs subsequent processing.

Various methods have been proposed and tested for recovering hydrogen isotopes from water [1]. These include electrolysis, the water-gas shift reaction ( $\mathrm{CO}+$ $\left.\mathrm{H}_{2} \mathrm{O} \leftrightarrow \mathrm{CO}_{2}+\mathrm{H}_{2}\right)$ and metal reactions $\left(\mathrm{xM}+\mathrm{yH}_{2} \mathrm{O} \rightarrow\right.$ $\mathrm{M}_{\mathrm{x}} \mathrm{O}_{\mathrm{y}}+\mathrm{yH}_{2}$, where $\mathrm{M}$ is a metal atom). Processes which use metal reactions suffer from the disadvantage that they are generally irreversible (iron reactions are an exception). However, such processes are usually easy to construct and operate and, for small processing requirements, they may find utility.

Within the fusion fuel processing community, uranium has received considerable attention as a metal to be used for the recovery of hydrogen isotopes from water. However, more easy to obtain and use is the metal magnesium. This reacts with water according to,

$\mathrm{Mg}$ (solid) $+\mathrm{H}_{2} \mathrm{O}$ (gas) $\rightarrow \mathrm{MgO}$ (solid) $+\mathrm{H}_{2}$ (gas)

The use of this reaction to produce $D_{2}$ gas from deuterated water has been reported [2]. Thus, flowing $\mathrm{H}_{2} \mathrm{O}$ vapor over a $\mathrm{Mg}$ bed results in $\mathrm{H}_{2}$ gas at the bed outlet. Eventually the entire bed is converted to $\mathrm{MgO}$ and must be discarded.

Work has been conducted at the Tritium Systems Test Assembly (TSTA) at Los Alamos National Laboratory to show that $\mathrm{Mg}$ is effective for recovering tritium from tritiated water. This work was done as part of the Annex IV collaboration between the US Department of Energy/TSTA and the Japan Atomic Energy Research Institute/Tritium Processing Laboratory. 'Two sets of experiments were performed. Fi-st, a set of bench-scale experiments were conducted to develop the techniques necessary for building a $\mathrm{Mg}$ bed. Then, a practical-scale $\mathrm{Mg}$ bed was built and installed as part of the Fuel CleanUp system for testing with tritium 
and to show that it could work in conjunction with the other fuel processing systems. This paper will describe and discuss these two sets of experiments.

\section{EXPERIMENTAL DESCRIPTION, RESULTS AND DISCUSSION}

\section{A. Bench-Scale Experiments}

Reactions with metals such as $\mathrm{Mg}$ in packed bed reactors can suffer from sintering or from incomplete conversion due to insufficient reactive surface area. Thus, the first step in this research was the construction of a small test stand built around a quartz tube reactor. Into this reactor various combinations of $\mathrm{Mg}$ powder (a single mixture with particle sizes ranging between 50 and 100 mesh) and coarse turnings were packed. The reactor was heated to various temperatures and fed inert gas which had been humidified using a bubbler. The reactor inlet pressure was monitored. The reactor exhaust was passed through color-indicating "drierite" desiccant before being released to a Los Alamos atmosphere ( $\sim 590$ torr).

It was found that neither the extreme of pure powder or pure turnings produced acceptable results. The powder-only packed reactor was effective at converting all of the water to $\mathrm{H}_{2}$ as indicated by no change in the drierite color over the course of the experiment. However, over time the inlet pressure would begin to increase, indicating that the bed was plugging possibly due to sintering. Packed with all turnings, the bed would not plug, but water would pass through the bed unconverted as evidenced by a drierite color change. This configuration likely did not have enough surface area to sufficiently react with the water. Thus, it was determined that a mixture of powder and turnings was in order. It was concluded that a mixture composed of $\sim 75 \%$ powder and $\sim 25 \%$ turnings produced good results.

Another purpose for these experiments was to determine a proper reactor operating temperature. A temperature of at least $350^{\circ} \mathrm{C}$ was required to avoid the formation of magnesium hydroxide. Temperatures which were greater than $480^{\circ} \mathrm{C}$ led to plugging problems, even with the powder/turnings mix. Temperatures below $440^{\circ} \mathrm{C}$ resulted in incomplete water conversion. Thus, it was concluded that $440-480^{\circ} \mathrm{C}$ was an acceptable operating temperature range.

\section{B. Practical-Scale Demonstration}

Using the data from the bench-scale experiments a practical-scale, tritium-compatible $\mathrm{Mg}$ bed was constructed. A drawing of this bed is shown on figure 1 . Though shown horizontally, the bed is actually operated in the vertical position. The outer dimensions are 17.5" long $\times 3$ " diameter. All reactor parts are 304 stainless steel. Packed inside both ends of the vessel is stainless steel wool. This leaves an approximately 15 " long section packed with $75 \%$ powder $/ 25 \%$ turnings magnesium. The total weight of magnesium used was 1113 grams. In addition to the steel wool, $2 \mu$ filters are used to ensure that $\mathrm{Mg}$ does not migrate into adjoining tubing. Two 836 watt heating tapes wired in parallel were wrapped around the reactor shell. Four layers of fiberglass insulation tape were added on top of the heating tape. A thermowell down the center of the reactor was used to determine bed temperature. During the testing described below, substantially elevated glovebox tritium levels were observed and this is believed to be due to permeation of tritium through the reactor wall. The addition of a vacuum jacket to the $\mathrm{Mg}$ bed design would mitigate this problem.

This reactor assembly was installed in the Fuel CleanUp (FCU) glovebox. Figure 2 shows the portion of the TSTA FCU into which the magnesium bed was installed. The MSBFs (molecular sieve bed freezers) and the MSBs (molecular sieve beds) collect impurities (water, methane, nitrogen, etc.) and produce impuritiesfree hydrogen isotopes which are sent to the cryogenic distillation-based ISS (isotope separation system). When the MSBFs and MSBs are regenerated, the desorbed

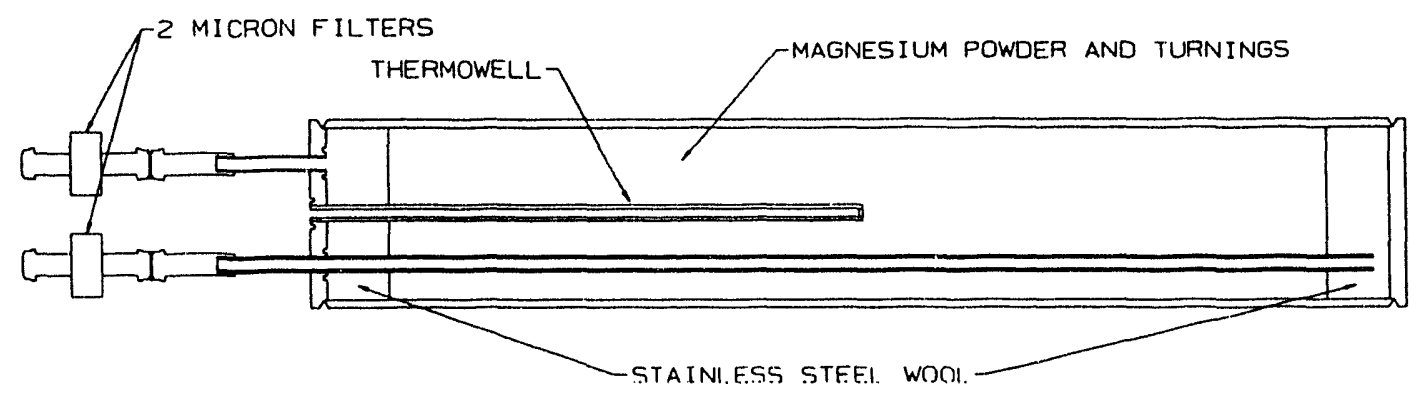

Figure 1 Practical Scale Mg Bed Used at TSTA 


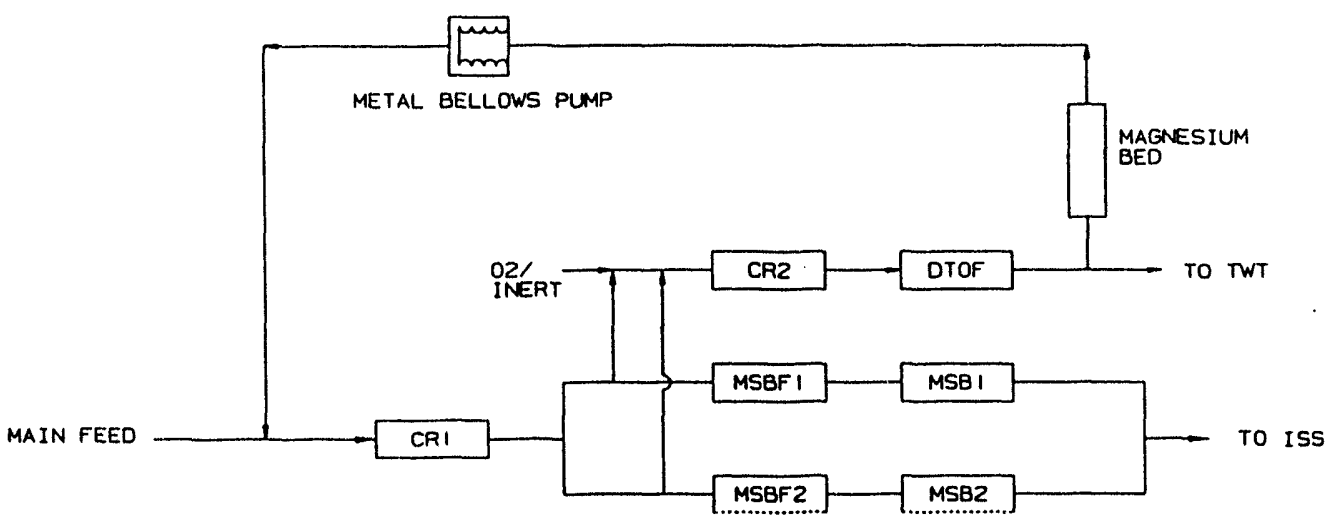

Figure 2 Location of the Magnesium Bed in the TSTA FCU

impurities are mixed with oxygen and sent to CR2 (catalytic reactor). There, tritium in all forms is converted to water. This water is collected in the DTOF (deuterium tritium oxide freezer) and the remaining tritium-free waste is sent to the TWT (tritium waste treatment) system. The final step in this process is the regeneration of the DTOF. A portion of the hydrogen isotopes from the main flow path (CR1-MSBF-MSB) is used to sweep water from the DTOF into the magnesium bed. The water reacts with $\mathrm{Mg}$ leaving the free hydrogen isotopes in the gas phase. These are returned to the main flow path with the aid of a metal bellows pump. Excluding the magnesium bed, operational results using the other FCU components have been reported previously [3].

The first test of this magnesium bed was in December 1989. There was a quantity of approximately $100 \mathrm{cc}$ of liquid tritiated water remaining in the DTOF from a previous experiment. The magnesium bed was used to successfully recover the hydrogen isotopes from this water.

The next test of the magnesium bed came in March 1992. This test oxidized 0.217 moles of $\mathrm{CH}_{4}$ which was collected as water in the DTOF. This water was subsequently processed using the magnesium bed. The result was that 0.728 moles of hydrogen isotopes were recovered which is considerable more than the 0.434 moles that should have been recovered if the process were $100 \%$ efficient. This discrepancy could have been due to a number of factors, but there was not an opportunity to resolve this. Nonetheless, the qualitative result was that the magnesium bed was effective at recovering hydrogen isotopes from methane, using a water intermediate.

Subsequently the magnesium bed was used during an April 1992 TSTA "loop" experiment. This was a three- week long campaign during which the various TSTA subsystems, including the ISS and FCU, were interconnected and tested as a total system. Part of this test included the addition of $10 \% \mathrm{CH}_{4} / 90 \% \mathrm{~N}_{2}$ to the DT main loop flow which simulated fusion reactor effluent. The simulated impurities were collected on the FCU MSBs. Thereafter, the concentrated impurities were processed using the CR2-DTOF train so that all hydrogen isotopes in all forms were converted to water and collected in the DTOF. This water was processed with the magnesium bed.

A detailed history of the DTOF regeneration is given on figures 3 through 7 . The regeneration flow from the DTOF through the $\mathrm{Mg}$ bed began on 4/25/92 at 17:30. As shown on figure 3, the temperature of the DTOF began at about $150 \mathrm{~K}$ and increased to about $310 \mathrm{~K}$ over the course of the regeneration. As shown on figure 4, the flowrate through the DTOF and Mg bed was 100 to 200 $\mathrm{sccm}$ at the beginning of the regeneration. Just before 18:00 this flowrate was increased to about $800 \mathrm{sccm}$. It was observed on figure 5 , that the flowrate increase caused an increase in the $\mathrm{Mg}$ bed temperature from about $704 \mathrm{~K}$ to about $707 \mathrm{~K}$. This is believed to be due to the additional heat of reaction as more water was reacting with the Mg. When the flowrate was decreased to 400$500 \mathrm{sccm}$, the $\mathrm{Mg}$ bed temperature also began to drop. The pressure history in the DTOF over the same time period is recorded on figure 6 .

Of particular interest is the humidity at the exit of the $\mathrm{Mg}$ bed during the regeneration which was measured with a humidity probe and is shown on figure 7. The humidity was reduced from its initial value of about $3{ }^{\circ} \mathrm{C}$ dew point before flow started to about $-30^{\circ} \mathrm{C}$ dew point. This indicates that the $\mathrm{Mg}$ bed is working effectively at processing the water from the DTOF. Then, abruptly at 20:25 the humidity increased dramatically and saturated the humidity probe which has a -80 to $+20^{\circ} \mathrm{C}$ dew point 
range. This is interpreted to be due to all of the $\mathrm{Mg}$ having been converted to $\mathrm{MgO}$. Having nothing to react with, the water "breaks through" the bed exit. This very sharp breakthrough curve indicates that the $\mathrm{Mg} \rightarrow \mathrm{MgO}$ reaction front in the bed is very sharp. This behavior is desirable, since all of the $\mathrm{Mg}$ is completely consumed at breakthrough and, thus, none is wasted. As soon as breakthrough was detected, the regeneration was terminated and the $\mathrm{Mg}$ bed was prepared for disposal.

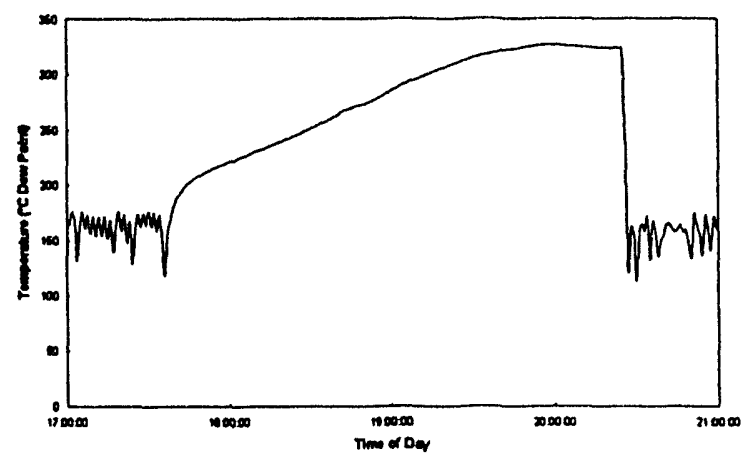

Figure 3 Temperature of the DTOF during 4/25/92 Water Processing

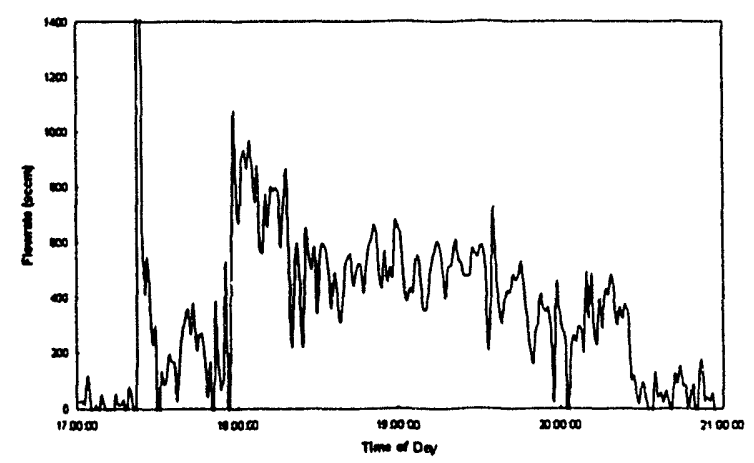

Figure 4 Flowrate through the DTOF-Mg Bed during 4/25/92 Water Processing

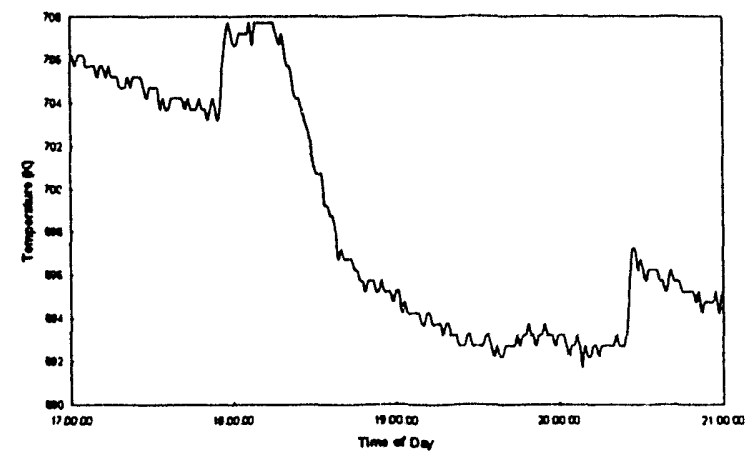

Figure 5 Temperature of the Magnesium Bed during 4/25/92 Water Processing

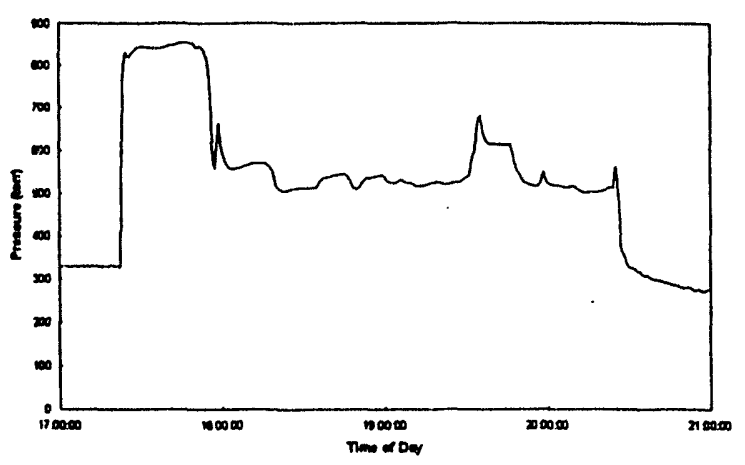

Figure 6 Pressure of the DTOF during 4/25/92 Water Processing

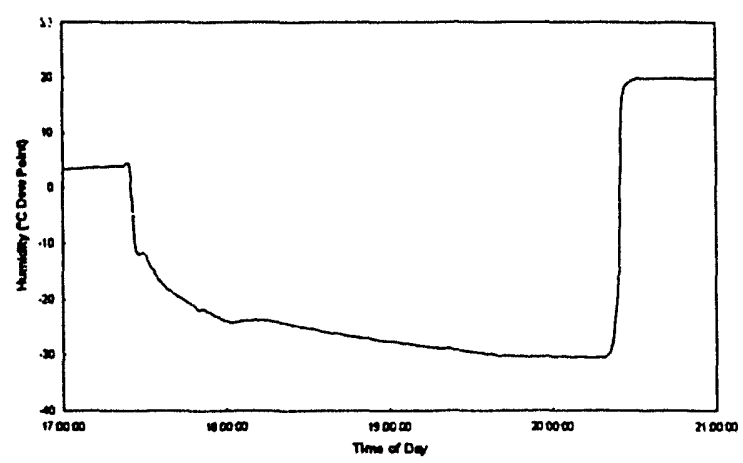

Figure 7 Humidity at the Magnesium Bed Exit during 4/25/92 Water Processing

\section{CONCLUSIONS}

Bench-scale experiments using only protiated water demonstrated that a $\mathrm{Mg}$ bed was effective for recovering hydrogen from water. These experiments concluded that a bed should be operated between 440 and $480^{\circ} \mathrm{C}$. An acceptable bed packing was found to be $75 \% \mathrm{Mg}$ powder and $25 \% \mathrm{Mg}$ turnings. This set of parameters resulted in good conversion without bed plugging.

A tritium-compatible $\mathrm{Mg}$ bed was designed, constructed and installed in the TSTA FCU subsystem. It was found to be effective at recovering all hydrogen isotopes from water $(\mathrm{H}, \mathrm{D}$ and $\mathrm{T})$. Good efficiency for water processing was evidenced by low humidities at the $\mathrm{Mg}$ bed exit. When all $\mathrm{Mg}$ was consumed, the humidity breakthrough that was observed was very sharp, indicating that $\mathrm{Mg}$ oxidation is favorable and complete, resulting in essentially no wasted $\mathrm{Mg}$.

The $\mathrm{Mg}$ bed was relatively simple to build and operate. Based on this limited set of data, it appears that $\mathrm{Mg}$ is at least as effective as $\mathrm{U}$ for recovering tritium from tritiated water. Due to fewer regulations, $\mathrm{Mg}$ is easier to obtain and use. Both materials, however, suffer 
from being unregenerable once oxidized. Once used, these metal beds must be disposed of as tritiated waste. This makes them impractical for large-scale use, but they may find appropriate use for limited-scale operations.

\section{REFERENCES}

[1] Willms, R. S., S. Konishi, "Fuel Cleanup Systems for Fusion Fuel Processing", Fusion Engr. \& Design, $18,53-60$ (1991).

[2] Knowlton, John W., Frederick D. Rossini, "Method and Apparatus for the Rapid Conversion of Deuterium Oxide into Deuterium", J. of Research of the National Bureau of Standards, 19, 605 (1937).

[3] Willms, R. S., J. L. Anderson, J. L. Bartlit, Y. Naruse and K. Okuno, "Fusion Fuel Purification, During the Tritium Systems Test Assembly 3-Week Loop Experiment", Proceedings of the $13^{\text {th }}$ IEEE Symposium on Fusion Engineering, Knoxville, TN, pp. 795-797, October 2-6, 1989. 

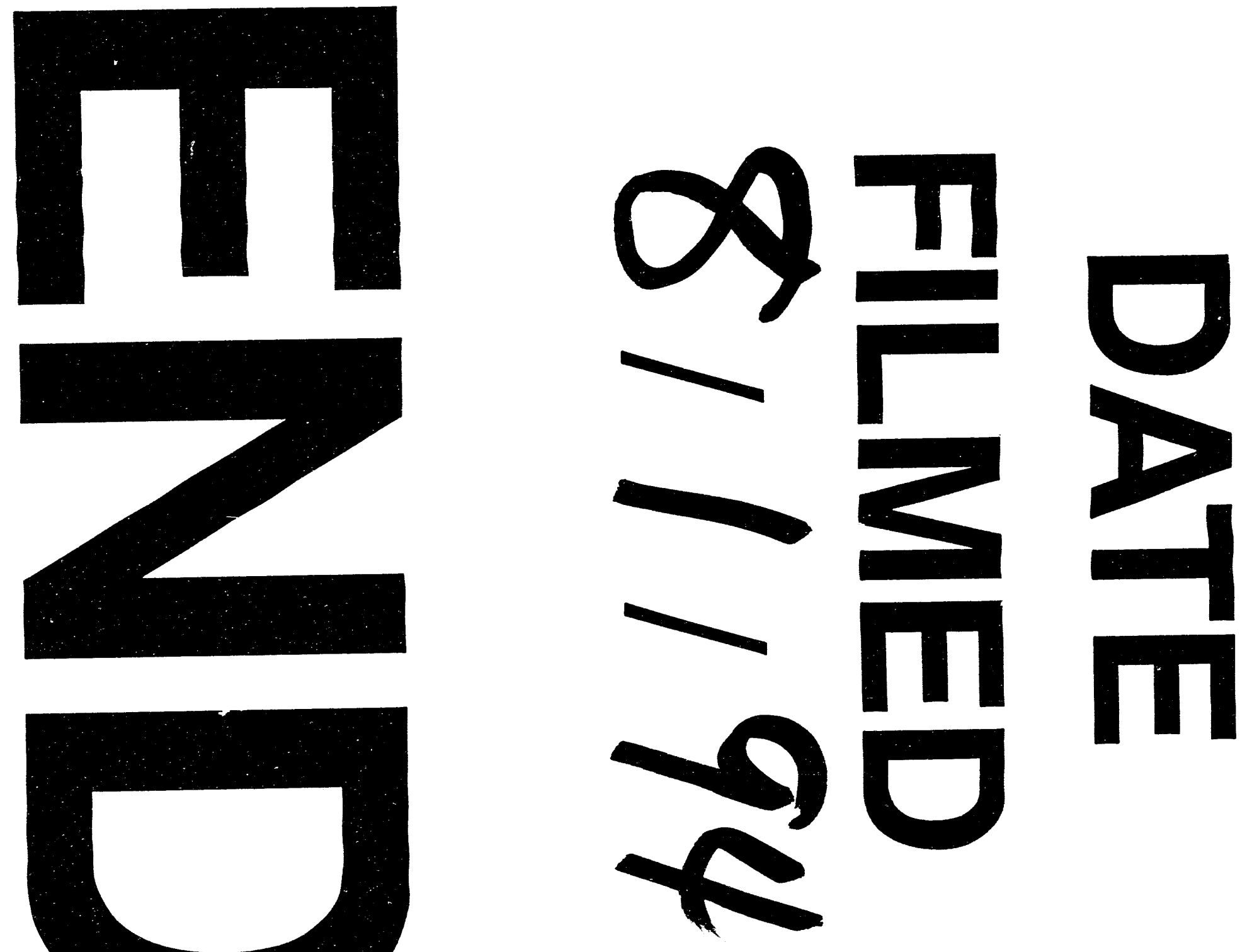
$$
\text { ט. }
$$

列
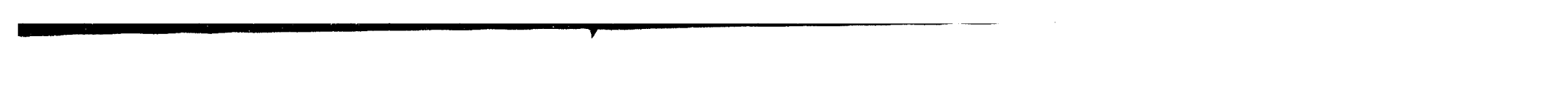